\title{
Economic Efficiency of Smallholder Farmers in Teff Production: The Case of Enemay District, East Gojjam Zone, Amhara Region, Ethiopia
}

\author{
Mekuriaw Yesgat* \\ Commercial Bank of Ethiopia, Bichena Branch, Bichena, Ethiopia \\ Yenetila Alamneh $(\mathrm{PhD})$ \\ Department of Agricultural Economics, Debre Markos University, Ethiopia
}

\begin{abstract}
Agriculture remains to be the most important sector of the Ethiopian economy and teff is one of the dominant crops which is produced at less efficient level in the study area. This means that it is possible to obtain additional output from existing inputs used, if resource are properly used and efficiently allocated. The aim of this study was to assess the economic efficiency of smallholder teff producers and identify factors affecting efficiency of smallholder farmers in teff production of Enemay District, Amhara Regional State of Ethiopia. A two-stage sampling technique was employed to select 197 sample farmers who were interviewed using a structured schedule to obtain data pertaining to teff production during 2018/2019 production season. Cobb-Douglas production function was fitted using stochastic production frontier approach to estimate technical, allocative and economic efficiency levels, whereas Tobit model was used to identify factors affecting efficiency levels of the sample farmers. The estimated results showed that the mean technical, allocative and economic efficiencies were $81 \%, 11 \%$ and $9 \%$, respectively which indicates the significant inefficiency in teff production in the study area. Among factors hypothesized to determine the level of efficiencies, education, soil fertility, credit and teff production experience were the positively significant determinants of technical and economic efficiencies of teff producing farmers; while frequency of extension contact had a positive relationship with technical efficiency. In addition, cultivated land determined farmers' technical, allocative and economic efficiencies negatively and significantly. Whereas distance to market determined technical and economic efficiencies negatively. The result indicated that there is a room to increase the efficiency of teff producers in the study area. Hence, emphasis should be given to improve the efficiency level of those less efficient farmers by adopting the practices of relatively efficient farmers in the area. Beside this, policies and strategies of the government should be directed towards the above mentioned determinants.
\end{abstract}

Keywords: Teff, efficiency, Cobb-Douglas, Stochastic frontier, Tobit

DOI: $10.7176 / \mathrm{JAAS} / 68-04$

Publication date:September $30^{\text {th }} 2020$

\section{INTRODUCTION}

For most developing countries, enhancing the total production and productivity is not an option rather it is the first priority in their policies. Production and productivity can be basically boosted using two ways. The first method is through increased use of inputs and/or improvement in technology given some level of input. The other option of improving productivity is to enhance the efficiency of producers or firms, given fixed level of inputs and technology. This study is mainly concerned with the second option of increasing efficiency of producers. The measurement of efficiency has remained an area of important research, especially in developing countries, where resources are scanty and opportunities for developing by inventing and or adopting better technologies are dwindling (Hagoes, 2014).

About $80 \%$ of Ethiopia's population of 100 million lives in rural areas. Agriculture is the dominant sector in the economy, accounting for 35\% of Gross Domestic Product (GDP), 65\% of employment, and over $80 \%$ of the country's export values (World Bank Report, 2019; Central Statistics Agency, 2017/18, cited in Agricultural Transformation Agency (ATA), 2018/2019 annual report.

In developing countries like Ethiopia, agricultural production and productivity is low and the agricultural output growth were imbalance with population growth. In Ethiopia there are high potential areas which can produce enough grains to meet the needs of the deficit areas. However, lack of efficiency in agricultural systems makes farmers not to produce more as it is expected (Yimenu, 2017).

According to Moges (2014), in highlands of Ethiopia, the demand for land has been increasing significantly for the last three decades. Available evidences show that over the 4 years, the total land holding per household is becoming smaller and smaller. With $2.9 \%$ population increase and consequent degradation of natural resources, the opportunity to increase smallholders' productivity through area expansion should not be expected. Evidences, especially in developing agricultural economies where resources and technologies are scarce, 
show that measuring efficiency is highly important so as to improve production and productivity with a given level of resources.

According to Solomon (2014), agricultural output can be increased either through introduction of modern technologies or by improving the efficiency of inputs such as labor and land at the existing technology. In other words, productivity can be increased through spreading of improved technologies and/or by improving the productive capacity of farmers. These two are not mutually exclusive, because the introduction of modern technology could not bring the expected shift of production frontier, if the existing level of efficiency is low. This implies the need for the integration of modern technologies with improved level of efficiency.

According to Musa (2014), efficiency measures are important since it is a factor for maximizing productivity. Such studies benefit economies by determining the extent to which it is possible to raise productivity by improving the neglected source of growth (efficiency) with the existing resource base and available technology. Understanding the existence of efficiency differentials and different factors contributing to the inefficiency in advance is a factor that helps to improve efficiency with a view to bring a desired change in the sector. However, there is limited number of studies done in this regard in general and most of the studies show a narrow focus in terms of sampling.

The majority of farm efficiency studies in agricultural economics also focus on technical efficiency (Coelli, et al., 2002) which is one component of overall economic efficiency. However, profit maximization requires a farm to produce the right mix and optimal output given the level of inputs employed.

Teff (Eragrostis tef), a warm-season annual cereal, is one of the underutilized crops that can contribute to food security and crop diversification. Teff contains high and unique nutritional values, which will meet the need of health-conscious consumers. It is also a low risk crop, which resists many biotic and abiotic stresses. Currently, Ethiopia is the largest teff producing country, and the only country to have adopted teff as a staple crop. However, the teff production and value chain in Ethiopia largely rely on traditional practices, and the teff market is limited by the government's export ban. Instead, other countries such as USA are increasingly participating in the teff market (World Bank Report, 2019; Central Statistics Agency, 2017/18, cited in Agricultural Transformation Agency (ATA), 2018/2019 annual report.

Ethiopia is the largest teff producer in the world. In 2017, Teff accounts for $24 \%$ of the grain area, followed by maize $17 \%$ and sorghum $15 \%$ ). Amhara and Oromia are the two major regions, and collectively, the two regions account for $85.5 \%$ of the teff area and $87.8 \%$ of the teff production.

Teff is the second most widely produced and consumed cereal in Ethiopia. Teff has remained an important crop to Ethiopian smallholder farmers for several reasons, namely: the price for its grain; the crop performs better than other cereals under moisture stress and waterlogged conditions; its grain can be stored for a long period of time without being attacked by weevils (Solomon, 2014). However, its output is relatively low (around 1.4 ton per hectare) and high loss rates (25-30 percent both before and after harvest) decrease the quantity of grain available to consumers by up to 50 percent (CSA, 2014). This holds true for the region in which this study is undertaken.

The study area, Enemay District, is among the major teff producing zones i.e East Gojjam Zone of the Amhara Region. Maximizing the efficiency of teff production of smallholder farmers must be mandatory so as to reduce their poverty level.

\section{RESEARCH METHODOLOGY}

\section{Descriptions of the Study Area}

Enemay District is found in east Gojam Administrative Zone of the Amhara National Regional State, Ethiopia. It is bordered on the south by Dejen, on the west by Debay Tilatgin, on the north by Enarj Enawga, and on the east by Shebel Berenta districts. The capital of Enemay District is Bichena town located at about 265 kilometers in the northeast direction from Addis Ababa. Geographically, the district is located $10039^{\prime} 59.99^{\prime \prime} \mathrm{N}$ latitude and $38^{\circ} 00^{\prime}$ 0.00 " E longitudes.

\section{Research Design and Strategy}

The types of research under this study were descriptive and explanatory. The major purpose of descriptive research is description of the state of affairs as it exists at present. Then the study describes and critically assesses economic efficiency of teff production of smallholder farmers. With regard to the data, both primary and secondary sources were used. The primary data pertaining to the production year 2018/2019 were collected from sample respondents through a structured questionnaire, which was designed to generate data on relevant social, institutional and economic variables. The enumerators who speak the local language and live within the study kebeles (the smallest administrative unit of Ethiopia) were recruited and trained on methods of data collection and interviewing techniques. Secondary data were obtained from Enemay District Office of Agriculture and related institutions, and other published and unpublished materials, which were found to be relevant for the study. 


\section{Sampling Technique and Sample Size}

Two stages random sampling procedure was employed to draw a representative sample. In the first stage, four kebeles have been selected purposively since they are large producers of teff as compared to others. In the second stage, smallholder farmers were stratified into teff producers and non-producers. Consequently, 197 teff producers were selected randomly.

\section{Methods of Data Analysis}

Descriptive and econometric methods of data analyses were employed in this study. Descriptive statistics are important to have a clear picture of the characteristics of sample units. This method of data analysis refers to the use of ratios, percentages, means, and standard deviations in analyzing the socio-economic characteristics of the farmers, input and output variables and the distribution of efficiency levels. Whereas, the stochastic frontier production function model of Cobb-Douglas functional form was employed to estimate the firm-level technical and allocative efficiencies of the farmers in the study area.

\section{Efficiency Estimation Methods}

The stochastic production frontier was used to distinguish inefficiency from deviations that are caused by factors beyond the control of farmers. The model introduces the disturbance term representing noise, measurement error and exogenous shocks that are beyond the control of the production and a component that captures deviations from the frontier due to inefficiency.

The assumption that all deviations from the frontier are associated with inefficiency, as assumed in DEA, is difficult to accept, given the inherent variability of agricultural production due to many factors like climatic hazards, plant pathology, insect and pests (Coelli and Battese, 1995).

Furthermore, smallholder farmers in Ethiopia are characterized by low level of education and keeping of records is thus non-existent. Thus, most available data on production are likely to be subject to measurement errors. Therefore, the stochastic efficiency decomposition methodology is chosen as more appropriate for this study.

While a number of alternative approaches are available to analyze efficiency, the stochastic frontier approach is often recommended because it is the only one which allows deviation of an observation from the frontier due to both inefficiency and random noise. Without such accommodation, statistical noise is counted as inefficiency (Squires and Tabor, 1991).

The stochastic frontier production function model of Cobb-Douglas functional form is employed to estimate the firm-level technical and allocative efficiencies of the farmers in the study areas. The Cobb-Douglas functional form was used because: the functional form has been widely used in farm efficiency analysis for the developing and developed countries, the functional form meets the requirement of being self-dual, allowing an examination of economic efficiency and lastly Kopp and Smith (1980) suggested that functional form has a limited effects on empirical efficiency measurement.

The Cobb-Douglas production functional form which specifies the production technology of the farmers is expressed as follows:

$\mathrm{Y}_{\mathrm{i}}=\mathrm{f}\left(\mathrm{X}_{\mathrm{i}} ; \beta_{\mathrm{i}}\right) \exp \mathrm{V}_{\mathrm{i}}-\mathrm{U}_{\mathrm{i}}$

Where $Y_{i}$ represents the quantity of output, $X_{i}$ represents the quantity of input used in the production and $\beta_{i}$ a vector of parameters to be estimated. The $V_{i}$ are assumed to be independent and identically distributed random errors, having normal $\mathrm{N} \sim\left(0, \sigma_{\mathrm{v}}^{2}\right)$ distribution and are independent of the $\mathrm{U}_{\mathrm{i}} \mathrm{s}$. The $\mathrm{U}_{\mathrm{i}} \mathrm{s}$ are technical inefficiency effects, which are assumed to be non-negative truncation of the half-normal distribution $\mathrm{N} \sim\left(\mu, \sigma_{u}^{2}\right)$.

The technical efficiency of individual farmers is defined in terms of the ratio of observed output to the corresponding frontiers output, conditional on the level of input used by the farmers. Hence, the technical efficiency of a farmer is expressed as:

$\mathrm{TE}_{\mathrm{i}}=\frac{Y_{i}}{Y_{i}^{*}}=\frac{f\left(X_{i} ; B_{i}\right) \exp \left(V_{i}-U_{i}\right)}{f\left(X_{i} ; B_{i}\right) \exp \left(V_{i}\right)}=\exp \left(-U_{i}\right)$

Where: $\mathrm{Y}_{\mathrm{i}}$ is the observed output and $\mathrm{Y}_{\mathrm{i}}{ }^{*}$ is the frontiers output. The TE ranges between 0 and 1 .

The corresponding cost frontier of Cobb-Douglas functional form which is the basis of estimating the allocative efficiencies of the farmers is specified as follows:

$\mathrm{C}_{\mathrm{i}}=\mathrm{g}\left(\mathrm{P}_{\mathrm{i}} ; \alpha\right) \exp \left(\mathrm{V}_{\mathrm{i}}+\mathrm{U}_{\mathrm{i}}\right) ;=1,2 \ldots . \mathrm{n}$

Where $\mathrm{C}_{\mathrm{i}}$ represents the total input cost of the $\mathrm{i}^{\text {th }}$ farms; $\mathrm{g}$ is a suitable function such as the Cobb-Douglas function; $P_{i}$ represents input prices employed by the $i^{\text {th }}$ farm in milk production and measured in Birr; $\alpha$ is the parameter to be estimated, $V_{\mathrm{i}} \mathrm{S}$ and $\mathrm{U}_{\mathrm{i}} \mathrm{s}$ are random errors and assumed to be independent and identically distributed truncations (at zero) of the $\mathrm{N}\left(\mu, \sigma^{2}\right)$ distribution. $\mathrm{U}_{\mathrm{i}}$ provides information on the level of allocative efficiency of the $\mathrm{i}^{\text {th }}$ farm. Allocative inefficiency occurs if the ratio of the marginal physical products of two inputs does not equal the ratio of their prices. The allocative efficiency of individual farmers is defined in terms of the ratio of the predicted minimum cost $\left(\mathrm{C}_{\mathrm{i}}^{*}\right)$ to observed $\operatorname{cost}\left(\mathrm{C}_{\mathrm{i}}\right)$. That is: 
$\mathrm{AE}_{\mathrm{i}}=\frac{C_{i}^{*}}{C_{i}}=\exp \left(\mathrm{U}_{\mathrm{i}}\right)$

Hence, the value of allocative efficiency ranges between 0 and 1 .

Given the assumptions of the above stochastic frontier model, inference about the parameters of the model can be based on the maximum-likelihood estimators because the standard regularity conditions hold. Aigner et al. (1977) suggested that the maximum-likelihood estimates of the parameters of the model be obtained in terms of the parameterization, $\sigma_{\mathrm{v}}^{2}+\sigma_{\mathrm{u}}{ }^{2}=\sigma^{2}$ and $\lambda=\frac{\sigma_{u}}{\sigma_{v}}$. Rather than using the non-negative parameter, $\lambda$ (i.e., the ratio of the standard deviation of the $\mathrm{N}\left(0, \sigma^{2}\right)$ distribution involved in specifying the distribution of the non-negative $v_{\mathrm{is}}^{\prime}$ to the standard deviation of the symmetric errors, $v_{\mathrm{i}}$ ), Battese and Corra (1977) considered the parameter, $\gamma=$ $\frac{\sigma_{u}{ }^{2}}{\sigma_{v}{ }^{2}+\sigma_{u}{ }^{2}}$

Which is bounded between zero and one

To determine the relationship of socioeconomic and institutional factors with efficiency indices Tobit model was employed. The Tobit model was employed because efficiency scores were truncated 0 and 1 as the score lies within the range of 0 and 1.

Where,

The Tobit model was defined as:

$$
y i=\beta 1+\sum \beta n X j n+\mu j
$$

$Y_{i}=$ latent variable which shows efficiency score of farm $\mathrm{j}$

$\beta=$ vector of unknown parameter,

$X j n=$ vector of explanatory variable $\mathrm{n}(\mathrm{n}=1,2.3,4 \ldots . \mathrm{n})$ for farm $\mathrm{j}$ and $\mathrm{uj}$ an error term that is independently and normally distributed with mean zero and variance $\partial^{2}$.

$Y i=$ shows the observed variables.

$$
\begin{gathered}
Y i=1 \text { if } \mathrm{yix} \geq 1 \\
Y i \text { if } 0<\mathrm{yix}<1 \\
0 \quad \text { if } \mathrm{yix} \leq 0
\end{gathered}
$$

This shows that the distribution of the dependent variables is not normally distributed, while values vary between 0 and 1.

\section{RESULTS AND DISCUSSION \\ Descriptive Analysis}

This study used both continuous and dummy variables to explain the variation in output due to technical and allocative inefficiency. The summary of continuous variables used in the model prevailed that the average output produced by sample plot owners was found to be about 1854 kilograms and on average 5.53 laborers were employed to produce the output. On average farmers cultivated 1.38 hectares of land with $27.51 \mathrm{~kg}$ of seed and 4.66 kilograms of fertilizer. In addition, farmers have on average 1.96 oxen and 8.02 livestock (as measured in TLU). Farmers' participation in teff production on average is 9.89 years; getting extension contact 3.39 times in the production season and the farmers are far from the market location on average $2.43 \mathrm{~km}$ (Table 1).

\section{Table 1: Summary of continuous variables for analysis}

\begin{tabular}{lccccc}
\hline Variables & Units & Mean & Std. Dev. & Min & Max \\
\hline Out put & Kilogram & 1854 & 615 & 500 & 3000 \\
Labor & Man-day & 5.53 & 1.34 & 2 & 9 \\
Seed & Kilogram & 27.51 & 10.17 & 5 & 60 \\
Land for teff production & Hectare & 0.62 & 0.27 & 0.25 & 1.5 \\
Fertilizer & Kilogram & 4.66 & 1.76 & 1 & 10 \\
Oxen & Number & 1.96 & 0.72 & 1 & 4 \\
Extension contact & Number & 3.39 & 1.67 & 0 & 8 \\
Distance to market & Kilometer & 2.43 & 1.89 & 0.5 & 4 \\
Livestock holding & TLU & 8.02 & 2.76 & 3 & 35 \\
Farming experience & Year & 9.89 & 6.30 & 1 & 30 \\
Total land & Hectare & 1.38 & 0.27 & 0.25 & 2 \\
\hline
\end{tabular}

This study also used dummy variables to explain the variation in output due to technical and allocative inefficiency. The summary of dummy variables used in the model prevailed that on average $61.93 \%$ of the land allocated for teff production is fertile while $38.07 \%$ is not fertile. $62.94 \%$ of the farmers were not credit users and 
$37.06 \%$ were beneficiaries of formal and informal credit sources. And $28.43 \%$ of the farmers uneducated while 71.57 of them were educated (Table 2).

Table 2: Summary of dummy variables for analysis

\begin{tabular}{llll}
\hline Variables & Units & Frequency & Percent \\
\hline Soil fertility & $1=$ fertile & 122 & 61.93 \\
& $0=$ non-fertile & 75 & 38.07 \\
Education & $1=$ educated & 141 & 71.57 \\
& $0=$ uneducated & 56 & 28.43 \\
Credit & $1=$ yes & 73 & 37.06 \\
& $0=$ no & 124 & 62.94 \\
\hline
\end{tabular}

\section{Econometric Results}

The stochastic production frontier was applied using the maximum likelihood estimation procedure. The dependent variable of the estimated model was teff output produced in 2018/129 production season and the input variables used in the analysis were area under teff), animal draught power, labor, quantity of seed, and inorganic fertilizers specifically DAP and UREA. To include those farmers who did not apply DAP and urea in the estimation of the frontier a very small value that approach zero was assigned for non-users of fertilizer.

Prior to model estimation, a test was made for multicollinearity among the explanatory variables used in the model by using the Variance Inflation Factor (VIF). In a production function analysis, correlation between some of the explanatory variables is expected and collinearity among economic variables is an inherent and age-old problem leading to problems of multicollineariy. Some have suggested that multicollinearity is not necessarily a problem unless it is very high (Gujarati, 1995). However, the values of VIF for all variables entered into the model were below 10, which indicate the absence of severe multicolinearity among the explanatory variables. In addition, Breusch-Pagan test was also used to detect the presence of hetroskedasticity and the test indicated that there was no problem of hetroskedasticity in the models.

Table 3: Estimates of the Cobb Douglas frontier production function

\begin{tabular}{llll}
\hline Output & Coefficient & Std. Err. & $\mathrm{Z}$ \\
Land & .1896075 & .0273442 & $6.93^{* * *}$ \\
Labor & -0.0007805 & .0087875 & -0.09 \\
Seed & .4129982 & .0310219 & $13.31^{* * *}$ \\
Fertilizer & .2357022 & .0343514 & $6.86^{* * *}$ \\
Oxen & .0086306 & .1200591 & 0.072 \\
Constant & 1.241395 & .1200591 & $10.34^{* * *}$ \\
Lambda & 0.72839 & 0.125454 & $5.81^{* * *}$ \\
Sigma square & .2859242 & .0226926 & $12.60^{* * *}$ \\
\hline
\end{tabular}

$* * *, * *$ and $*$ show significance at $1 \%, 5 \%$ and $10 \%$ probability level, respectively

Source: Model output

\section{Tests of hypothesis}

Before estimation of the parameters from which individual level of efficiencies are estimated, it is better to examine various assumptions related to the model specification. To do this, two hypotheses were tested. The first test was to examine whether the average production function (without considering the non-negative random error term) does not fit the data so as to verify there exists considerable inefficiency among farmers in the production of teff in the study area. The other hypothesis that was to check whether the explanatory variables in the inefficiency effect model contribute significantly to the explanation of the technical inefficiency variation for the teff growing farmers. This was done based on the log likelihood ratio test (Table 4).

Table 4. Generalized likelihood ratio tests of hypothesis for the parameters of SPF

\begin{tabular}{llll}
\hline Null hypothesis & $\Lambda$ & Critical value $\left(\chi^{2}, 0.95\right)$ & Decision \\
Ho: $\gamma=0$ & 15.4 & 3.84146 & Rejected \\
Ho $=\delta 1=\delta 2=\delta 3=\delta 4 \ldots \ldots=0$ & 36.43 & 22.36 & Rejected \\
\hline
\end{tabular}

The likelihood ratio obtained from the log likelihood functions of both the average response function and the stochastic production function was found to be greater than the critical value. As a result, the null hypothesis that the average response function (OLS specification) is an adequate representation of the data was rejected and the alternative hypothesis that stated there exists considerable inefficiency among sample farmers was accepted.

The other hypothesis was also tested in the same way by calculating the likelihood ratio value using the value of the log likelihood function under the stochastic frontier model (without explanatory variables of inefficiency effects, $\left.\left(\mathrm{H}_{0}\right)\right)$ and the full frontier model with variables that are supposed to determine inefficiency level of each farmer, $\left(\mathrm{H}_{1}\right)$. The $\lambda$ value obtained was again higher than the critical $\times 2$ value at $95 \%$ degree of freedom equal to the number of restrictions. As a result, the null hypothesis is rejected in favor of the alternative hypothesis that the 
explanatory variables associated with inefficiency effects model are simultaneously different from zero. Hence, these variables simultaneously explain the difference in inefficiency among teff producing farmers in the study area.

\section{Efficiency Scores}

As indicated in Table 5, farmers in the study area were relatively good in technical efficiency than in economic or allocative efficiency. The mean TE was found to be $81 \%$ indicating that there was a $19 \%$ allowance for improving efficiency.

Table 5 also shows that the mean allocative efficiency of teff producer farmers in the study area was $11 \%$ indicating that there is a need to improve the present level of allocative efficiency. The results imply that if the average farmer in the sample was to achieve the allocative efficiency level of his or her most efficient counterpart in the study area, he or she would realize $21.43 \%(1-0.11 / 0.14) * 100$ more efficiency. The most allocative inefficient farmer would have an efficiency gain of $28.57 \%(1-0.1 / 0.14)^{*} 100$ to attain the level of the most technically efficient farmer.

The mean economic efficiency showed that there was a significant level of inefficiency in the production process. That is the producer with a minimum economic efficiency level could improve his or her efficiency level by about $61.54 \%(1-0.05 / 0.13) * 100$ as compared to the most efficient farmer. The result also indicated that the farmer with average level of economic efficiency would enjoy a cost saving of about 30.77\% (1-0.09/0.13)*100 to attain the level of the most efficient farmer.

Table 5. Summary of descriptive statistics of efficiency measures

\begin{tabular}{lllll}
\hline Efficiency & Min. & Max. & Mean & Std. Deviation \\
TE & 0.41 & 0.99 & 0.81 & 0.11 \\
AE & 0.10 & 0.14 & 0.11 & 0.01 \\
EE & 0.05 & 0.13 & 0.09 & 0.01 \\
\hline
\end{tabular}

Source: Own computation (2020)

\section{Determinants of efficiency differentials among farmers}

After measuring levels of smallholder farmers efficiency and determining the presence of efficiency differences among farmers, finding out factors causing efficiency deferential among farmers was the next most important step of this study. To see this, efficiency levels of sample farmers were regressed on factors that were expected to affect efficiency levels using a Tobit estimation procedure.

The result of the model showed that educational level of household head, access to credit, soil fertility, total land, distance to the market, and farming experience were important factors influencing economic efficiency of farmers in the study area. The model also revealed that total land significantly influenced allocative efficiency of teff producer farmers (Table 6).

Table9. Maximum likelihood estimates of the Tobit model

\begin{tabular}{lcccccc}
\hline \multirow{2}{*}{ Variables } & \multicolumn{2}{c}{ TE } & \multicolumn{2}{c}{ AE } & \multicolumn{2}{c}{ EE } \\
\cline { 2 - 7 } & Coefficient & Std. Err & Coefficient & Std. Err & Coefficient & Std. Err \\
\hline Education & $0.063337 * * *$ & 0.01473 & -0.0001149 & 0.0011544 & $0.00669^{* * *}$ & 0.001899 \\
Soil fertility & $0.03905^{* *}$ & 0.016949 & -0.000048 & 0.0013279 & $0.00446^{* *}$ & 0.002184 \\
Credit & $0.05298^{* * *}$ & 0.015629 & 0.00104 & 0.0012252 & $0.00669^{* * *}$ & 0.002016 \\
Total Land & $-0.036047^{* *}$ & 0.017325 & $-0.0041^{* *}$ & 0.0013573 & $-0.0075^{* * *}$ & 0.002233 \\
Extension & $0.025514^{*}$ & 0.01485 & -0.0013 & 0.0011633 & 0.002489 & 0.001913 \\
Distance & to & & & & & \\
market & $-0.0247976^{*}$ & 0.014889 & -0.001288 & 0.0011665 & $-0.00346^{* *}$ & 0.001919 \\
Livestock & -0.02544 & 0.026873 & 0.0026378 & 0.002094 & -0.000346 & 0.003444 \\
Farming & & & & & & \\
experience & $0.02278^{*}$ & 0.011732 & 0.0011957 & 0.0009191 & $0.003317^{* *}$ & 0.001511 \\
Constant & $0.74741^{* * *}$ & 0.064875 & $0.103136^{* * *}$ & 0.005065 & $0.07648^{* * *}$ & 0.0083317 \\
\hline
\end{tabular}

$* * *, * *$ and $*$ represents significant levels at $1 \%, 5 \%$ and $10 \%$ respectively

Source: Model output (2020)

The coefficient for educational level was significant and the variable was positively related to technical and economic efficiencies at one percent significance level. The result indicates that, economic efficiency require better knowledge and managerial skill. The positive sign indicates that increase in human capital enhances the efficiency of farmers. The sign was as expected because the more educated the farmers are the more will be the likelihood of being efficient in resource allocation. Similar results were obtained in the works of Musa (2014).

Access to credit had a positive and statistically significant effect on both farmers' technical and economic efficiency at one percent probability level, which indicates that farmers with access to credit tend to exhibit higher levels of efficiency. Credit availability shifts the cash constraint outwards and enables farmers to make timely 
purchases of those inputs that they cannot provide from their own sources.

The result also found that soil fertility was positively and significantly related to technical and economic efficiency at 5\% significance level. This implies that farmers who allocated a land which was relatively fertile were good in technical and economic efficiency. Therefore, decline in soil fertility could be taken as cause for significant output loss. The result is in line with the arguments of Alemayehu (2010) and Musa (2014).

Total land size had statically significant negative relationship with farmers' allocative efficiency. As the farm size of a farmer increases the managing ability of him/her will decrease given the level of technology, this lead to reduce the efficiency of the farmer. Accordingly, the estimated result coincides with the expectation and that coefficients of this efficiency variable found negative and statistically significant. That means total area cultivated by a household affected economic efficiency level negatively and significantly at $1 \%$ level of significance. The result is similar with the previous study by Moges (2014).

Frequency of extension contact had statistically significant positive relationship with technical efficiency at $10 \%$ significance level as it was expected. This implies that a frequent contact facilitates the flow of new ideas between the extension agent and the farmer thereby giving a room for improvement in farm efficiency. Advisory service rendered to the farmers in general can help farmers to improve their average performance in the overall farming operation as the service widens the household's knowledge with regard to the use of improved agricultural inputs and agricultural technologies. This result is also similar to the study by Mbanasor and Kalu (2008).

Distance from home to the nearest market was also significant in determining technical and economic efficiency of farmers at $10 \%$ and $5 \%$ significance level, respectively. The negative coefficient implies that farmers far from markets are less technically efficient compared to their counterparts who reside nearby markets. This might be due to the fact that as farmers are located far from market, there would be limited access to input and output markets and market information. Moreover, higher distance to market leads to higher transaction cost that reduces the benefits that accrue to the farmer. Similar result was found in the work of Alemu et al. (2008).

The coefficient for experience on teff production was significant and the variable was positively related to technical and economic efficiencies at $10 \%$ and $5 \%$ significance level, respectively. The result indicates that, experienced farmers would acquire knowledge and skills that are required for prudent resource allocation. The result was found to be similar with Moges (2014).

\section{CONCLUSIONS AND POLICY IMPLICATIONS Conclusions}

This study asses the economic efficiency of teff producers in Enemay District of Amhara Regional state of Ethiopia. The study employed the stochastic frontier approach and both primary and secondary data were used. Primary data were collected through household survey from a sample of 197 households using structured questionnaire. Secondary data were collected from relevant sources to support the primary data. Data analysis was carried out using descriptive statistics and econometric techniques.

The Cobb-Douglas stochastic frontier production and its dual cost functions were estimated from which TE, $\mathrm{AE}$ and EE were extracted. The results from the production function showed that land, fertilizer and seed were positively and statistically significant. The study also indicated that $81 \%, 11 \%$ and $9 \%$ were the mean levels of $\mathrm{TE}, \mathrm{AE}$ and EE, respectively indicating that there was $19 \%, 89 \%$, and $91 \%$ allowance for improving $\mathrm{TE}, \mathrm{AE}$, and EE, respectively.

In the second step of the analysis, relationships between TE, AE, and EE, and various variables expected to have effects on farm efficiency were examined. This was relied on Tobit regression techniques, where TE, AE, and EE were expressed as functions of 8 independent variables. Among them education, soil fertility, frequency of extension contact, credit and distance to market were found to be statistically significant to affect the level of technical efficiency. The model showed that education, soil fertility, credit, frequency of extension contact, teff production experience and distance to market were important factors that affect economic efficiency of farmers in the study area. The study also revealed that cultivated land significantly influence the allocative efficiency of smallholders in the study area.

\section{Policy implications}

The study reveals that teff producers in the study area are not operating at full technical, allocative and economic efficiency levels and the result indicated that there is ample opportunity for teff producers to increase output at existing levels of inputs and minimize cost without compromising yield with present technologies available at the hands of producers.

The study found that different types of efficiencies and their determinants were found to be different and allocatiive and economic efficiency were found to be low. Therefore, intervention aiming to improve efficiency of farmers in the study area has to be given due attention for resource allocation in line with output maximization as there is big opportunities to increase output without additional investment.

Education was very important determining factor that has positive and significant impact to both technical 
and economic efficiency in the study area. It is central to adopt and use modern agricultural technologies and practices, agricultural information and institutional accessibilities which improve farm households' efficiencies. Thus government has to give due attention for training farmers through strengthening and establishing both formal and informal type of framers' education, farmers' training centers, technical and vocational schools as farmer education would reduce both technical and economic inefficiencies.

Access to credit has a positive influence on both technical and economic efficiencies. Therefore, better credit facilities have to be produced via the establishment of adequate rural finance institutions and strengthening of the available micro-finance institutions and agricultural cooperatives to assist farmers in terms of financial support through credit so as to improve farm productivity.

Soil fertility is a crucial factor in determining technical efficiency of farmers. Therefore, farmers have to work to improve the fertility status of the land though it is difficult to achieve this in the short run. Farmers can do this by applying artificial fertilizer (compost) and fertilizers (DAP \& urea) that are suitable for the farm and practicing soil conservation practices. Policy makers need also to have soil fertility maintenance program and extension workers can play a great role in improving the status of the soil by working closely with the farmers in this regard.

Distance to market has a significant influence on the technical and economic efficiency of smallholders. Therefore, farmers have to get inputs easily and communication channels have to be improved to get better level of efficiency.

Extension contact has positive and significant contribution to technical efficiency. Since extension services are the main instrument used in the promotion of demand for modern technologies, appropriate and adequate extension services should be provided and strengthened.

\section{REFERENCES}

Agricultural Transformation Agency (ATA), 2018. Annual report

Aigner, D.J., C.A.K. Lovell and P. Schmidt, 1977. Formulation and estimation of stochastic frontier production function models. Journal of Economics, 6(1): 21-37.

Battese, G.E., and G.S. Corra, 1977. Estimation of a production frontier model: with application to pastoral zone of eastern Australia. Australian Journal of Agricultural Economics 2(3):169-179.

Alemayehu Ethiopia, 2010. Analysis of Factors Affecting the Technical Efficiency of Coffee Producers in Jimma Zone: A Stochastic Frontier Analysis. M.Sc. Thesis Presented to the School of Graduate Studies of Addis Ababa University.

Alemu Bamlaku, A. Nuppenau and H. Boland, 2008. Technical Efficiency of Farming Systems across Agroecological Zones in Ethiopia: An Application of Stochastic Frontier Analysis. PhD Dissertation presented to Department of Environmental Management and Market Research, Justus-Liebig University of Giessen, Germany.

Coelli, T., S. Rahman, and C. Thirtle, 2002. Technical, Allocative, Cost and Scale Efficiencies in Bangladesh Rice Cultivation: A Non-parametric Approach. Journal of Agricultural Economics, 53(3): 607-626.

Central Statistical Agency of the Federal Democratic Republic of Ethiopia. (2005a, 2006a... 2014a). Agricultural Sample Survey: 2004/5, 2005/6... 2013/14 (1997, 1998... 2006 E.C.) Volume IV: Report on Land Utilization (Private Peasant Holdings, Meher Season). Addis Ababa, Ethiopia.

Gujarati, D.N., 1995. Basic Econometrics. Third edition. Mc Graw Hill, Inc. New York.

Hagoes Weldegebriel, 2014. The Determinants of Technical Efficiency of Farmers inTeff, Maize and Sorghum Production: Empirical Evidence from Central Zone of Tigray Region. Ethiopian Journal of Economics Vol. XXIII No 2, October 2014.

Kopp, R.J. and V.K. Smith, 1980. Frontier production function estimation for steam electric generation: A comparative analysis. Southern Econometric Journal, 47: 1049-59.

Mbanasor, J.and K.C. Kalu, 2008. Economic Efficiency of Commercial Vegetable Production System in Akwa Ibom state, Nigeria. Journal of Tropical and Subtropical Agro ecosystems, 8(3):313-318.

Moges Dessale., 2014. Technical efficiency in teff production: the case of Smallholder farmers in jamma district, south Wollo zone, Ethiopia. M.Sc. Thesis presented to the School of Graduate Studies of Haramaya University.

Musa Ahmed, 2014. Technical efficiency of maize producing farmers in Arsi Negelle, Central rift valley of Ethiopia. Journal of Agriculture and Forestry.

Squires, D., and S. Tabor, 1991. Technical efficiency and future production gains in Indonesian agriculture. The developing economies, XXIX-3: 258-270.

Yimenu Kassa, 2017. Determinants of technical efficiency in maize production of smallholder farmers; the case of Fogera district, south Gondar zone, Ethiopia, . M.Sc. Thesis presented to the School of Graduate Studies of University of Gondar. 